${ }^{1}$ Erciyes Üniversitesi, Kayseri,

Türkiye,sevaltaser@gmail.com

ORCID: 0000-0003-1975-4673

${ }^{2}$ Doç. Dr., Erciyes Üniversitesi, Kayseri, Türkiye, kumruuyar@erciyes.edu.tr

ORCID: 0000-0002-2604-5317

SorumluYazar/Corresponding Author:

Seval Taşer Polat,

Erciyes Üniversitesi, Kayseri,

Türkiye,sevaltaser@gmail.com

Başvuru/Submitted: 29/10/2021

Revizyon/Revised: 8/12/2021

Kabul/Accepted: 16/12/2021

Yayın/Online Published: 25/12/2021

Atıf/Citation: Taşer Polat, S., \& Uyar, K.,Online perakende terapi: Tüketicilerin duygu durumlarına göre perakende terapi düzeylerinin incelenmesi, tujom (2021) 6

(3):206-222, doi:

https://doi.org/10.30685/tujom.v6i3.137

\section{Online perakende terapi: Tüketicilerin duygu durumlarına göre perakende terapi düzeylerinin incelenmesi}

\author{
Online retail therapy: Examination of retail therapy levels according to \\ consumers' moods
}

\author{
Seval Taşer Polat ${ }^{1}$ \\ Kumru Uyar ${ }^{2}$
}

Öz

$\mathrm{Bu}$ araştırmanın amacı tüketicilerin olumlu ve olumsuz duygu durumlarının online perakende terapi üzerindeki etkisini incelemektir. Araştırma verileri online alışveriş yapan tüketicilerden, 7-21 Nisan 2021 tarihleri arasında toplanmıştır. Çalışmada 466 kullanılabilir veri elde edilmiştir. Çalışmada olumlu duyguların online perakende terapi üzerinde etkisi olduğu sonucuna ulaşılmıştır. Online perakende terapi ölçeğinin boyutları incelendiğinde ise olumlu duygu durumunun; terapatik alışveriş motivasyonları, pozitif duygu takviyesi ve terapatik alışveriş sonucu üzerinde pozitif yönde etkiye sahipken negatif duygu durumu azalması üzerinde ise istatistiksel olarak anlamlı bir etkisinin olmadığı sonucuna ulaşılmıştır. Çalışmada ayrıca olumsuz duygu durumlarının da online perakende terapi üzerinde etkisi olduğu sonucuna ulaşılmıştır. Yine perakende terapi ölçeğinin alt boyutları incelendiğinde olumsuz duygu durumlarının terapatik alışveriş motivasyonları ve pozitif duygu takviyesi üzerinde etkisinin olmadığı görülmüştür. Buna karşın negatif duygu durum azalması ve terapatik alışveriş sonucu üzerinde etkisi olduğu sonucuna ulaşılmıştır. Analiz sonucunda elde edilen bulgular ışığında, tüketicilerin duygu durumlarının online perakende terapi düzeyi üzerindeki etkisine ilişkin yorumlar sunulmuş ve araştırma kısıtları belirtilmiştir.

Anahtar Kelimeler: Perakende Terapi, Olumlu Duygu Durumları, Olumsuz Duygu Durumları Цel Kodları: M31

\begin{abstract}
The purpose of this study is to examine the effects of consumers' positive and negative moods on online retail therapy. Research data were collected from online shopping consumers between April $7-21,2021$. Four hundred sixty-six usable data were obtained. In the study, it was concluded that positive emotions affect online retail therapy. When the dimensions of the online retail therapy scale were examined, it was seen that positive mood had a positive effect on therapeutic shopping motivations, positive emotion reinforcement and therapeutic shopping outcome variables. However, it was concluded that positive emotions did not significantly affect the decreased negative mood. Therefore, it was supposed that negative attitudes also impact online retail therapy. When the subdimensions of the therapy scale in retail were examined, it was seen that negative emotional states had no impact on therapeutic shopping motivations and positive emotion reinforcement. On the other hand, it was concluded that it affected harmful mood reduction and therapeutic shopping motivations. According to the findings obtained from the analysis, comments on the effect of consumers' emotional states on the retail therapy level were presented, and the research limitations were stated.
\end{abstract}

Keywords: Retail Therapy, Positive Emotional Mood, Negative Emotional Mood

Jel Codes: M31 


\section{ExtendedAbstract}

\section{Online retail therapy: Examination of retail therapy levels according to consumers' moods}

\section{Literature}

The term of Retail Therapy is the thought of a person going shopping and buying a small reward to cheer themselves on. It is believed that individuals are susceptible to retail therapy to elevate their mood. Adapting this concept to retail space is often referred to as "retail therapy" (Atalay ve Meloy, 2011, p. 639). Studies have found that increased consumption reduces stress functions as a therapy that improves mental symptoms without medication or surgery (Atalay \& Meloy, 2011, p. 639; Rick, Pereira \& Burson, 2014). Retail therapy is shopping to alleviate negative moods (Kacen, 1998). The importance of retail therapy has been recognized in retail businesses and the daily lives of consumers (Kang \& Johnson, 2011, p. 4).

On the other hand, emotions affect the shopping value, consumer visits and future purchases. Marketers and consumer researchers have focused on emotions a lot in recent years. Although the psychology literature acknowledges the specific role of negative emotions in shopping behaviour, less marketing research focuses specifically on negative emotions and their effects. But it is crucial to understand how emotional responses affect consumers is essential for marketers (Babin, Griffin, Borges, \& Boles, 2013, p. 472). It has been suggested that positive and negative emotions can facilitate consumer decision-making and play a critical role in the choice. From a psychological perspective, the consumer's emotional response in consumption should be explicitly studied because it is as important as the cognitive process in understanding consumer behaviour (Koshkaki \& Solhi, 2016, p. 120).

\section{Research subject}

This study focuses on the effect of positive and negative moods of consumers on online retail therapy levels.

\section{Research purpose and importance}

This study examines the effects of consumers' positive and negative emotional states on online retail therapy. This research is vital in addressing the online retail therapy issue, which has been studied in the foreign literature and has never been studied in the Turkish literature. Findings to be obtained after the analysis are essential in measuring the effect of positive and negative moods of consumers on online retail therapy and giving ideas and suggestions to retailers and brands on this subject. In addition, it is also vital in terms of shedding light on future studies on this subject.

\section{Contribution of the article to the literature}

There is no study on online retail therapy in the Turkish literature. In addition, in terms of examining both positive and negative emotions together.

\section{Design and method}

\section{Research type}

The study is applied research. It also has a causal and descriptive design

\section{Research problems}

The main problem of the research is to reveal the effect of joyous moods and negative moods of consumers on online retail therapy.

\section{Data collection method}

A questionnaire has been prepared to test this effect. Due to time and access restrictions, the questionnaire form was created and applied on the web. The sample consists of 473 participants, accessed by the convenience sampling method, non-random sampling methods. Therefore, the number of available data is 466 .

\section{Quantitative/qualitative analysis}

Before starting the analysis, a normality test was performed. Since the skewness and kurtosis values of the scales are in the range of $-/+1$ steals, the result is usually distributed. In the study, regression analysis was conducted to examine the effect of emotional states on retail therapy. First, the statements measuring the level of retail treatment were averaged. Next, the impact of joyous and negative moods on retail treatment was examined. Then, the effects of positive and negative attitudes on the subdimensions of the retail therapy scale were analysed separately.

\section{Research model}

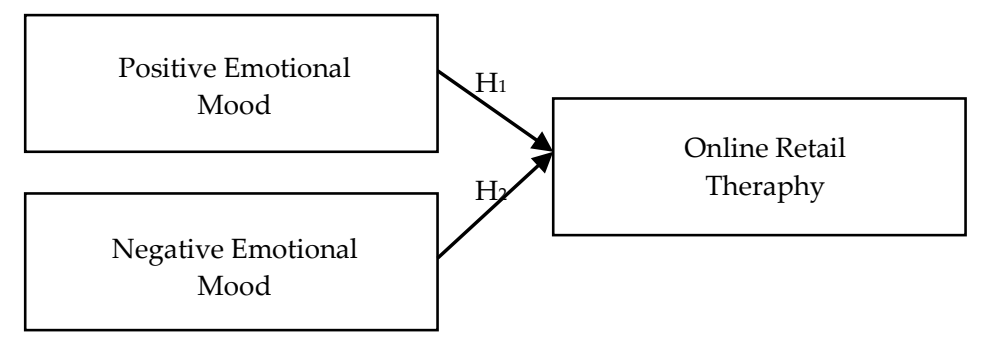

Figure 1: Measurement Model 


\section{Research hypotheses}

$\mathrm{H}_{1}$ : The positive mood of consumers has a statistically significant effect on online retail therapy.

$\mathrm{H}_{1 \mathrm{a}}$ : The positive mood of consumers has a statistically significant effect on the therapeutic shopping motivation variable.

$\mathrm{H}_{1 \mathrm{~b}}$ : Consumers' positive mood has a statistically significant effect on the therapeutic shopping value positive emotional reinforcement variable.

$\mathrm{H}_{11}$ : Consumers' positive moods statistically affect the therapeutic shopping value and negative mood reduction variable.

H1d: Consumers' positive mood has a statistically significant effect on the therapeutic shopping outcome variable.

$\mathrm{H}_{2}$ : Consumers' negative moods have a statistically significant effect on online retail therapy.

$\mathrm{H}_{2 a}$ : Consumers' negative moods have a statistically significant effect on the therapeutic shopping motivation variable.

$\mathrm{H}_{2 b}$ : The positive emotional reinforcement variable of consumers' negative moods statistically affect the therapeutic shopping value.

$\mathrm{H}_{2 c:}$ Consumers' negative moods significantly affect the therapeutic shopping value negative mood reduction variable.

$\mathrm{H}_{2 \mathrm{~d}}$ : Consumers' negative moods have a statistically significant effect on the therapeutic shopping outcome variable.

\section{Findings and discussion}

\section{Findings as a result of analysis}

It was seen that the scale used in the study met the validity and reliability conditions. In the study, it was concluded that positive emotions affect online retail therapy. Also, it was supposed that negative moods also affect online retail therapy. In other words, consumers can shop to feel good when they have negative emotions.

Hypothesis test results

\begin{tabular}{|l|l|}
\hline Hypothesis & Results \\
\hline $\mathbf{H}_{1}$ & Supported \\
\hline $\mathbf{H}_{1 \mathbf{a}}$ & Supported \\
\hline $\mathbf{H}_{1 b}$ & Supported \\
\hline $\mathbf{H}_{1} \mathbf{c}$ & Rejected \\
\hline $\mathbf{H}_{1 d}$ & Supported \\
\hline $\mathbf{H}_{2}$ & Supported \\
\hline $\mathbf{H}_{2 \mathbf{a}}$ & Rejected \\
\hline $\mathbf{H}_{2 b}$ & Rejected \\
\hline $\mathbf{H}_{2 \mathbf{c}}$ & Supported \\
\hline $\mathbf{H}_{2 \mathbf{d}}$ & Supported \\
\hline
\end{tabular}

\section{Discussing the findings with the literature}

In the study, it was concluded that positive emotions affect online retail therapy. In other words, when consumers feel good, this good feeling can enable them to shop online. This result is supported by Lee's (2015) research. In addition, Gardner and Rook (1998) found that the emotion that encourages participants to shop is "pleasure" in their experimental study. However, When the dimensions of the online retail therapy scale were examined, it was seen that positive mood had a positive effect on therapeutic shopping motivations, positive emotion reinforcement and therapeutic shopping outcome variables. It was concluded that positive emotions did not have a statistically significant impact on the decreased negative mood. This may be because the participants already have positive feelings.

In the study, it was concluded that negative moods also affect online retail therapy. In other words, consumers can shop to feel good when they have negative emotions. This result is again consistent with the studies in the literature (Lee, 2015)(Gardner \& Rook, 1998)(Trampe \& Stapel, 2011). However, when the sub-dimensions of the therapy scale in Percane were examined, it was seen that negative emotional states did not affect therapeutic shopping motivations and positive emotion reinforcement. On the other hand, it was concluded that it affected harmful mood reduction and therapeutic shopping outcomes.

Since there is not much research on this subject in the literature, it is more difficult to compare and interpret the results. However, while online shopping has increased so much nowadays, the concept of retail therapy is an issue that companies should address.

\section{Conclusion, recommendation and limitations}

\section{Results of the article}

Initially, reliability analysis was performed on the scales. The positive emotional moods scale is measured with 15 expressions, and Cronbach's Alpha value is 0.914 . The negative emotional mood scale is measured with 13 statements, and Cronbach's Alpha value is 0.914 . The online retail therapy scale is measured with 22 expressions, and Cronbach's Alpha value is 0.963 . So all three scales are reliable. Before starting the analysis, a normality test was performed. Since the skewness and kurtosis values of the scales are in the range of $-/+1$ steals, the result is usually distributed. In the study, regression analysis was conducted to examine the effect of emotional states on retail therapy. First, the statements measuring the level of retail therapy were averaged. Next, the impact of joyous and negative moods on retail therapy was examined. Then, the effects of positive and negative attitudes on the sub-dimensions of the retail therapy scale were analysed separately. Positive emotions affect online 
retail therapy. Also, while a positive mood positively affects therapeutic shopping motivations, positive emotion reinforcement, and therapeutic shopping outcome, it does not significantly affect the decrease in a negative mindset. Negative attitudes also affect online retail therapy. Also, negative emotional states did not affect therapeutic motivations and positive emotion reinforcement. On the other hand, it was concluded that it impacts harmful mood reduction and therapeutic shopping outcomes.

\section{Suggestions based on results}

In future studies, researchers can examine this issue in terms of the demographic characteristics of consumers. In addition, in the foreign literature, the concept of retail therapy has often been studied with such topics as impulse buying behaviour and materialism. Therefore, research can be done by adding these variables.

\section{Limitations of the article}

The most important limitation of the study is that the results cannot be generalized since the data were collected by easy sampling, one of the non-random sampling methods. Therefore, another rule is that the data was collected online. 


\section{Giriş}

Tüketim toplumunun kültüründe, postmodern tüketiciler için ürünler fonksiyonel faydadan çok daha fazla anlamlar içermektedir. Tüketimin hedonik yönü artık çok daha anlamlıdır. Olumsuz duygu durumundaki kişiler kendilerini mutlu hissettirecek, rahatlatacak ve olumsuz ruh hallerini düzeltecek çözümler ararlar. Bu noktada ürünler ilk akla gelen çözüm alternatifleri olabilmektedir. Ruh halimizi düzenlemede ve kendimizi iyi hissetmede tüketim önemli bir rol oynamaktadır (Kacen, 1998; Andrade, 2005; Atalay ve Meloy, 2011). Duygularımız tüm davranışlarımızda etkili olduğu gibi tüketimimizde de etkilidir. Duygular, alışveriş değerini, tüketicinin ziyaretlerini ve gelecekteki satın alma şeklini etkilemektedir. Özellikle günümüzde duyguların tüketicileri nasıl etkilediğini anlamak pazarlamacılar için oldukça önemlidir (Babin, Griffin, Borges, ve Boles, 2013, s. 472). Olumlu ve olumsuz duygular tüketicilerin karar vermesini etkileyebileceği gibi alternatif seçiminde kritik bir rol de üstlenebilirler. Çünkü psikolojik faktörler tüketici davranışını anlama konusunda bilişsel süreçler kadar önemlidir (Koshkaki ve Solhi, 2016, s. 120).

Perakende terapi terimi bir bireyin alışverişe çıkması ve kendisini neşelendirmek için küçük bir ödül satın alması düşüncesini akıllara getirmektedir. Bireylerin, ruh hallerini iyileştirmelerinin bir yolu olarak perakende tedavisine duyarlı olduklarına inanılmaktadır. Bu kavramın perakende bağlamına uygulanması, genellikle "perakende terapisi" olarak adlandırılır (Atalay ve Meloy, 2011, s. 639). Araştırmalar stresi azaltmak için artan tüketimin, ilaç veya ameliyat olmaksızın zihinsel semptomları iyileştiren bir terapi türü olarak işlev gördüğünü bulunmuştur (Atalay ve Meloy, 2011; Rick, Pereira ve Burson, 2014). Perakende terapisi, olumsuz ruh hallerini hafifletmek için alışverişi ifade eder (Kacen, 1998). Tüketicilerin günlük yaşamlarında ve perakendeci işletmelerin faaliyetlerinde, perakende terapinin önemi kabul edilebilir hale gelmiştir (Kang ve Johnson, 2011, s. 4).

Ruh halini düzenlemek ve psikolojik faktörleri iyileştirmek için alışverişin duygusal ve psikolojik değeri hakkında önemli çalışmalar yapılmıştır (Atalay ve Meloy, 2011; Kacen ve Lee, 2002). Türkiye'de yapılan çalışmalar incelendiğinde perakende terapi konusunda sadece bir çalışmaya rastlamıştır ve bu çalışma kişilik özellikleri ile perakende terapi kavramını birlikte incelemiştir (Uyar, 2019). Ancak bu çalışmalarda geleneksel perakendecilik dikkate alınmıştır. Online perakende terapi konusunda sınırlı sayıda çalışmaya rastlanmıştır (Lee ve Lee, 2019). Online alışveriş arttıkça, online alışverişin duygusal ve psikolojik değeri hakkında daha fazla araştırmaya ihtiyaç duyulmaktadır.

Özellikle COVID-19 pandemi döneminde sokağa çıkma kısıtlamaları ve bulaş riskiyle bireyler online alışverişe yönelmiştir. Tüm Dünya'da online alışveriş rakamları inanılmaz bir hızda artmıştır. Türkiye'de 2020 yılında COVID-19 pandemisinin etkisiyle, online alışveriş harcamaları \%45 oranında artmıştır (TÜBISAD, 2020). Online perakendeciliğin önemi arttıkça bu alanda yapılan çalışmaların önemi artmaktadır.

Bu çalışmada olumlu ve olumsuz duygu durumlarının online perakende terapi üzerindeki etkisi incelenmektedir. Çalışmada kısa giriş bölümünden sonra, perakende terapi kavramına ve duygu durumlarına dair literatürde yer alan çalışmalara değinilmektedir. Sonraki aşamada, araştırma soruları ve hipotezlerden bahsedilmektedir. Ardından araştırma modeli, metodolojisi ve kısıtları anlatılarak son kısımda sonuçlar ve gelecek çalışmalar için öneriler bulunmaktadır.

\section{Literatür taraması}

\section{Perakende terapi}

Alışveriş, günlük hayatımızın önemli bir parçasıdır. Yaygın olarak, birçok tüketicinin olumsuz duygularını onarmak için bir araç olarak alışveriş ve satın alma yaptığı düşüncesi ileri sürülmektedir ve bu durum perakende terapisi olarak adlandırılmaktadır (Lee L. , 2015). Terapinin perakende bağlamına uygulanmasına perakende terapisi denir ve kişinin kendisi için satın alması konusunda yine kendisini teşvik etmesi olarak tanımlanmıştır (Atalay ve Meloy, 2011). Araştırmalar, alışverişin bir ürünün tüketici tarafından satın alınmasa da sadece ürünün seçilmesiyle bile negatif duyguları hafiflettiğini göstermektedir (Rick, Pereira ve Burson, 2014).

Bu nedenle, perakende satış terapisi, stresin sadece göz atarak bile hafifletilebilmesi ve tüketicilerin perakende terapisi yoluyla çeşitli psikolojik gelişmeler bekleyebilmesidir (Yurchisin, Yan, Watchravesringkan, ve Chen, 2006). Perakende terapi tüketicilerin, olumsuz ruh halini onarmak için 
bir strateji olarak veya olumsuz bir ruh haline (sinirlilik, stres ve karamsarlık) tepki olarak alışveriş yapmalarıdır.

Kang ve Johnson (2011) perakende terapisini kavramsallaştırdıkları çalışmada perakende terapi kavramına ait iki yaklaşım olan duygu durum hafifletici tüketim ve telafi edici tüketim kavramlarına değinmişlerdir. Bu çalışmada telafi edici tüketimin, ruh hali düzenletici tüketimden daha geniş bir yapı olduğu sonucuna varmışlardır. Ayrıca perakende terapinin kompulsif satın alma ile bazı ortak özellikleri paylaşan ayrı kavramlar olduğunu belirtmişlerdir. Telafi edici tüketim "bir kişi tatmin edemeyeceği bir ihtiyaç, eksiklik veya arzu hissettiğinde ve bu durumda satın alma davranışını alternatif bir tatmin aracı olarak kullandığında" ortaya çıkar. Kang ve Johnson (2011)'a göre perakende terapi kavramı terapatik alışveriş motivasyonları, terapatik alışveriş değeri pozitif duygu takviyesi, terapatik alışveriş değeri negatif duygu durumu ve terapatik alışveriş sonuçları değişkenlerini içeren bir kavramdır. Terapatik alışveriş motivasyonu, bireylerin alışveriş yapmaktan ve ürün satın almaktan kaynaklanan olumlu deneyimlerini ifade etmektedir. Terapatik alışveriş değeri pozitif duygu takviyesi, alışveriş yoluyla olumlu bir ruh halinin sürdürülmesini ifade etmektedir. Tüketicilerin alışveriş yaptıkça olumlu duygularında artış olduğu anlamına gelmektedir. Terapatik alışveriş değeri negatif duygu durum ise olumsuz ruh hallerini hafifletmek için alışveriş yapmayı ifade eder(Edwards, 1993).

Perakende terapi insanların negatif duygularını hafifletir. Kendini mutlu hisseden bireyler bu olumlu duygu durumunu korumaya ve hoş duygularını sürdürmeye çalışırlar. Terapatik alışveriş sonuçları, uzun vadeli faydalar sağlayan stratejik satın almaları ifade emektedir. Atalay ve Meloy (2011), terapatik alışveriş sonuçlarını, uzun vadeli ruh hali onarımı sağlayan plansız satın almalar veya alışveriş eklemeleri olarak tanımlamaktadır.

Kacen (1998), olumsuz bir ruh haline sahipken alışveriş yapan bireylerin, alışverişin duygularını geliştireceğini umarak sıklıkla kıyafet, aksesuar, elektronik ve yiyecek satın aldıkları sonucuna ulaşmıştır.

Atalay ve Meloy (2011) duygu durum yönetimi ile öz düzenleme literatürü arasındaki ilişkiyi incelemiştir. Bu çalışma perakende satış terapisinin olumsuz bir ruh halini düzeltmeye yönelik stratejik bir çabanın parçası olup olmadığına dair iç görü sağlamaktadır. Lee ve Lee (2019) online perakende terapisi ile tüketicilerin online moda alışveriş merkezlerine yönelik tutumları arasındaki ilişkiyi uyarıcı-organizma-tepki modeline göre incelemektedir.

Ko, Chun, Song, ve Mattila (2015)'ya göre alışverişin ruh halini hafifletme üzerindeki etkilerini incelemek için anlamsal ağ analizi uygulamışlardır. Noh ve Rakib(2017) perakende terapisi ile kompulsif satın alma ve istifçilik arasındaki ilişkiyi doğrulamıştır. Trampe ve Stapel (2011) tüketicilerin olumsuz ruh haline sahip olduğu zamanlarda dürtüsel satın almaya yöneldiğini tespit etmiştir.

Kumar ve Sultana(2017)alışveriş yoluyla rahatlık sağlama davranışının arkasındaki nedeni ve psikolojiyi anlamayı amaçlamıştır. Son ve Jung (2016) perakende terapinin kendi kendine hediye motivasyonu ve plansız satın alma eğilimi ile olumlu bir şekilde motive edilebileceği sonucuna ulaşılmıştır. Ayrıca bu çalı̧̧ma, kendi kendine hediye eğiliminin perakende terapisi üzerindeki etkisinin, planlanmamış satın alma eğiliminin etkisinden daha güçlü olduğunu ve fiyat bilincinin perakende terapisi üzerinde etkili olmadığını ortaya koymuştur.

Uyar (2019) kişilik özelliklerine göre perakende terapinin farklılık gösterip göstermediğini incelemiştir. Bu çalışmada nevrotik ve dürüst kişilik özelliklerine göre perakende terapinin farklılık gösterdiği sonucuna ulaşmıştır. Yani nevrotik ve dürüst kişilik özellikleri yüksek olan kişiler perakende terapiyi daha olumlu algılamaktadır. Diğer kişilik özelliklerinde ise perakende tüketim açısından istatistiksel olarak anlamlı bir farklılığa rastlanmamıştır.

Lee ve Yoo, (2021) terapatik değerlerin (olumlu ruh hali güçlendirme ve olumsuz ruh hali azaltma) terapatik alışveriş motivasyonunu önemli ölçüde etkilediğini tespit etmiştir. Ayrıca bu çalışmada terapatik alışveriş motivasyonu, terapatik alışveriş sonuçlarını olumlu yönde etkilediğini belirlemişlerdir. 


\section{Duygu durumları}

Duygu, olayların ve anlamlarının değerlendirilmesidir (Ortony, 1990). Duyguyu anlamak karmaşık olduğundan, araştırmacılar daha iyi bir şekilde anlaşılması amacıyla duyguyu sınıflandırmaya çalışmışlardır. Ortony ve Turner (1990), duygu üzerine yapılan çalışmaları gözden geçirmiş ve farklı araştırmacıların duyguları farklı yaklaşımlara göre inceledikleri ve kategorilere ayırdıkları sonucuna varmıştır. Bunlardan çoğu duyguları olumlu ve olumsuz olarak sinıflandırmaktadır. Laros ve Steenkamp (2005), bu duyguları olumlu ve olumsuz olarak kategorilere ayırmışlar ardından olumsuz duygular için 172 terim ve olumlu duygular için 140 terim belirlemişlerdir. Watson ve Clark'a (1988) göre olumlu duygu bir kişinin ne kadar coşkulu, aktif ve uyanık hissettiğini yansıtmaktadır. Yüksek olumlu duygu, yüksek enerji, tam konsantrasyon ve zevkli katılım durumudur, düşük olumlu duygu ise üzüntü ve uyuşukluk ile karakterizedir. Buna karşıllk, negatif duygular öfke, hor görme, tiksinti, suçluluk, korku ve sinirlilik dahil olmak üzere çeşitli caydırıcı ruh hali durumlarını kapsamaktadır. Düşük olumsuz duygu durumu, bir sakinlik durumudur. Bu iki faktör duygusal durum boyutlarını temsil eder. Bu düşünceden hareketle Watson ve Clarke çalışmalarında bu araştırmada da kullanılan ve olumlu ve olumsuz duygu durumlarını ölçen PANAS ölçeğini geliştirmiştir.

Literatürdeki çalışmaların bir kısmında duygu durumlarının anlık satın alma ile ilişkisi incelenmiştir. Lee'ye (2015) göre tüketicilerin, olumlu ve olumsuz ruh hallerine sahip olduklarında satın alma eğilimleri daha fazladır. Olumsuz duygu durumuna sahip tüketiciler kendilerini iyi hissetmek için satın alma eğilimi gösterebilirken, mutlu tüketicilerin görece kaprisli ve kaygısız davranma olasılığının daha yüksek olduğu ve bu davranışla satın almaya yöneldiği savunulmaktadır. Tüketicilerin stres veya depresyondan sonra kendi kendilerine hediye alarak kendilerini şımartmaya meyilli oldukları gözlemlenmiştir. Tersine, olumlu ruh hallerinde de dürtüsel satın alma yaygın olarak görülmektedir. Bu nedenle, olumlu bir duygusal durum, tüketicilerin karşılaştığ tekliflerin daha olumlu bir şekilde değerlendirilmesini sağlayabilir ve bu da tüketicileri satın almaya yöneltir. Kısacası, tüketiciler zaman zaman pembe gözlüklerle tüketim dünyasına bakarak, ruh haliyle uyumlu davranışlarda bulunabilmektedirler (Lee L. , 2015).

Rook ve Gardner (1998) bir grup tüketiciden, onları satın alım yapmaya teşvik eden bir ruh halini seçmelerini istedikleri zaman tüketiciler en çok "zevk", ardından "kaygısızlık" ve "heyecan" duygularını belirtmişlerdir. Nayebzadeh ve Jalaly (2014) araştırmalarında olumlu duygu durumu ve anlık satın alma eğilimleri arasında ilişki olduğu sonucuna ulaşmıştır. Trampe ve Stapel (2011) hem olumlu hem de olumsuz ruh hallerinin bir dizi farklı ürün için perakende satış terapisini arttırdığı sonucuna ulaşmıştır.

\section{Araştırma yöntemi}

\section{Araştırmanın özgün değeri}

Bu çalışma yabancı literatürde çok az çalışılan, Türkçe literatürde ise daha önce hiç çalışılmamış olan online perakende terapi kavramını incelemesi açısından özgündür. Ayrıca çalışma tüketicilerin olumlu ve olumsuz duygu durumlarının online perakende terapi üzerindeki etkisini ölçmesi bakımından literatüre katkı sağlar.

\section{Araştırma soruları}

Bu araştırma aşağıdaki soru ışığında oluşturulmuştur:

- Tüketicilerin olumsuz ve olumlu duygu durumlarının online perakende terapi üzerinde etkisi var midir?

\section{Araştırma hipotezleri}

Araştırmada yer alan hipotezler aşağıda ki gibi oluşturulmuştur:

H1: Tüketicilerin olumlu duygu durumlarmın online perakende terapi üzerinde istatistiksel olarak anlamlı bir etkisi vardır.

H1a: Tüketicilerin olumlu duygu durumlarının terapatik alışveriş motivasyonları değişkeni üzerinde istatistiksel olarak anlamlı bir etkisi vardır. 
Hib: Tüketicilerin olumlu duygu durumlarının terapatik alı̧veriş değeri pozitif duygu takviyesi değişkeni üzerinde istatistiksel olarak anlamlı bir etkisi vardır.

H1c: Tüketicilerin olumlu duygu durumlarının terapatik alı̧̧eriş değeri negatif duygu durumu azalması değişkeni üzerinde istatistiksel olarak anlamlı bir etkisi vardır.

Hı: Tüketicilerin olumlu duygu durumlarının terapatik alı̧̧eriş sonucu değişkeni üzerinde istatistiksel olarak anlaml bir etkisi vardir.

$\mathrm{H}_{2:}$ Tüketicilerin olumsuz duygu durumlarmın online perakende terapi üzerinde istatistiksel olarak anlaml bir etkisi vardır.

$\mathrm{H}_{2 a}$ : Tüketicilerin olumsuz duygu durumlarmın terapatik alı̧veriş motivasyonları değiş̧keni üzerinde istatistiksel olarak anlaml bir etkisi vardir.

$H_{2 b:}$ Tüketicilerin olumsuz duygu durumlarının terapatik alışveriş değeri pozitif duygu takviyesi değişkeni üzerinde istatistiksel olarak anlamlı bir etkisi vardır.

$\mathrm{H}_{2 c:}$ Tüketicilerin olumsuz duygu durumlarının terapatik alı̧̧eriş değeri negatif duygu durumu azalması değişkeni üzerinde istatistiksel olarak anlamlı bir etkisi vardır.

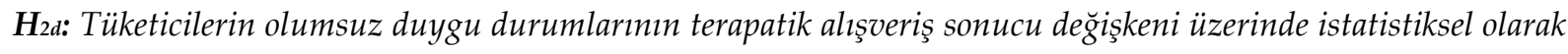
anlamlı bir etkisi vardır.

\section{Araştırma modeli}

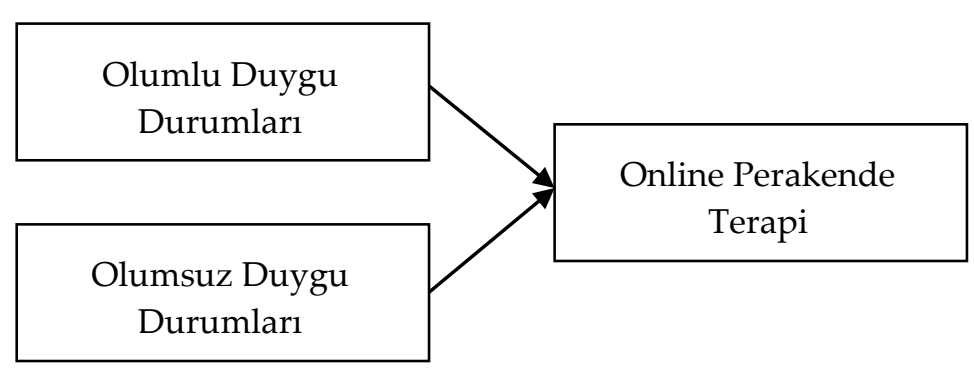

Şekil 1: Araştırma Modeli

Kaynak: Yazar tarafından üretilmiştir.

\section{Araştırmanın metodolojisi}

\section{Örneklem ve veri toplama tekniği}

Araştırmanın amacı, tüketicilerin olumlu ve olumsuz duygu durumlarının online perakende terapi düzeyleri üzerindeki etkisini incelemektir. Ölçüm için hazırlanan anket formu zaman ve erişim kıstı gibi sebeplerden dolayı web üzerinden online form oluşturularak uygulanmıştır. Örneklem tesadüfi olmayan örnekleme yöntemlerinden, kolayda örnekleme yönetimi ile ulaşılan 473 katılımcıdan oluşmaktadır. Sorulara verilen eksik ve çelişkili yanıtları içeren anketler çıkarılmıştır ve bu nedenle kullanılabilir veri sayısı ise 466 'dır. Verilerin kolayda örnekleme yöntemi ile toplanmış olması sebebiyle araştırma bulgularını genelleme konusunda dikkat edilmelidir.

\section{Veri Toplama Araçları}

Araştırmada veri toplamak amacıyla oluşturulan anket formu üç bölümden oluşmaktadır. İlk bölümde Watson ve Clark (1988)'ın çalışmasından alınan PANAS ölçeği kullanılmıştır. Bu ölçekte kullanıcıların olumlu duygu durumlarını ölçmek için 15 ifade ve olumsuz duygu durumlarını ölçmek için 13 ifade yer almaktadır. İkinci bölümde Kang ve Johnson (2011)'ın geliştirmiş olduğu ve Uyar (2019) tarafından Türkçeye uyarlanan perakende terapi ölçeği kullanılmıştır. Ölçek bu çalışma için online perakende terapi olarak uyarlanmıştır. Katılımcıların online perakende terapi düzeylerini ölçmek için 22 ifade yer almaktadır. Ankette 5'li Likert tipi ölçek kullanılmıştır (1=Kesinlikle Katılmıyorum, $5=$ Kesinlikle Katılıyorum). Anketin üçüncü bölümü katılımcıların demografik özelliklerini ölçmeye yönelik 6 sorudan oluşmaktadır. 


\section{Verilerin analizi ve bulgular}

\section{Katılımcıların demografik özellikleri}

Katılımcıların demografik özelliklerini görebilmek amacıyla cinsiyet, medeni durum, yaş, eğitim durumu, gelir durumu ve meslek gruplarını öğrenmeye yönelik sorulara verilen yanıtlara ilişkin dağılımlar Tablo 1'de gösterilmiştir.

Tablo 1: Katılımcıların Demografik Dă̆ılımları

\begin{tabular}{|c|c|c|c|}
\hline & & Frekans & $(\%)$ \\
\hline \multirow{2}{*}{ Cinsiyet } & Kadın & 349 & 74,9 \\
\hline & Erkek & 117 & 25,1 \\
\hline \multirow{2}{*}{ Medeni Durum } & Evli & 237 & 50,9 \\
\hline & Bekar & 229 & 49,1 \\
\hline \multirow{5}{*}{ Eğitim Durumu } & İlkokul & 27 & 5,8 \\
\hline & Lise & 81 & 17,4 \\
\hline & Ön Lisans & 22 & 4,7 \\
\hline & Lisans & 165 & 35,4 \\
\hline & Lisansüstü & 171 & 36,7 \\
\hline \multirow{4}{*}{ Yaş } & $19-30$ yaş arası & 280 & 60,1 \\
\hline & $31-40$ yaş arası & 109 & 23,4 \\
\hline & 41-50 yaş arası & 50 & 10,7 \\
\hline & 51 yaş ve üzeri & 27 & 5,8 \\
\hline \multirow{5}{*}{ Gelir Durumu } & $0-2.000$ TL aras 1 & 83 & 17,8 \\
\hline & 2.001-3.500 TL aras 1 & 88 & 18,9 \\
\hline & 3.501-5.000 TL aras1 & 138 & 29,6 \\
\hline & 5.001-6.500 TL aras1 & 46 & 9,9 \\
\hline & 6.501 TL ve üzeri & 111 & 23,8 \\
\hline \multirow{5}{*}{ Meslek } & Kamu & 142 & 30,5 \\
\hline & Özel Sektör & 221 & 47,4 \\
\hline & Ev Hanımı & 45 & 9,7 \\
\hline & Öğrenci & 49 & 10,5 \\
\hline & Çalışmıyor & 9 & 1,9 \\
\hline \multicolumn{2}{|l|}{ TOPLAM } & 466 & 100 \\
\hline
\end{tabular}

Katılımcıların \%74,9'unu kadınlar, \%25,1'ini ise erkekler oluşturmaktadır. \%50,9'u evli, \%49,1'i bekardır. Katılımcıların eğitim durumlarına bakıldığında \%5,8'i ilkokul mezunu, \%17,4'ü lise mezunu, $\% 4,7^{\prime}$ si ön lisans mezunu, \%35,4'ü lisans mezunu ve \%36,7'si lisansüstü mezunudur. Katılımciların çoğunluğu \%60,1 ile 19-30 yaş arasıdır. Gelir durumu açısından katılımcıların \%29,6's 3.501-5.000 TL aralığında ve \%23,8'i ise $6.501 \mathrm{TL}$ ve üzeri gelire sahiptir. Son olarak katılımcıların $\% 47,4^{\prime}$ ü özel sektör çalışanıdır.

\section{Araştırmada kullanılan ölçeklerin ortalama ve standart sapma değerleri}

Tablo 2: Olumlu Duygu Durumları Ölçeğinin Ortalama ve Standart Sapma Değerleri

\begin{tabular}{|l|c|c|}
\hline \multicolumn{1}{|c|}{ Değişkenler } & Ort. & Std. Sapma \\
\hline Son birkaç haftadır "İgiliyim" & 3,555 & 1,159 \\
\hline Son birkaç haftadır "Tetikteyim" & 3,152 & 1,265 \\
\hline Son birkaç haftadır "Heyecanlıyım" & 2,965 & 1,318 \\
\hline Son birkaç haftadır "Mutluyum" & 3,388 & 1,216 \\
\hline Son birkaç haftadır "Güçlüyüm" & 3,532 & 1,209 \\
\hline Son birkaç haftadır "Enerjiğim" & 3,105 & 1,358 \\
\hline Son birkaç haftadır "Sakinim" & 3,495 & 1,166 \\
\hline Son birkaç haftadır "Neşeliyim" & 3,324 & 1,180 \\
\hline Son birkaç haftadır "Aktifim" & 3,315 & 1,279 \\
\hline Son birkaç haftadır "Gururluyum" & 3,495 & 2,393 \\
\hline Son birkaç haftadır "Sevinçliyim" & 3,287 & 1,245 \\
\hline Son birkaç haftadır "Korkusuzum" & 3,154 & 1,322 \\
\hline Son birkaç haftadır "Memnunum" & 3,242 & 1,180 \\
\hline Son birkaç haftadır "Cesurum" & 3,349 & 1,263 \\
\hline Son birkaç haftadır "Canlıyım" & 3,296 & 1,213 \\
\hline
\end{tabular}


Katılımcıların olumlu duygu durumlarını ölçmek amacıyla oluşturulan ifadelere verilen yanıtlar incelendiğinde "son birkaç haftadır ilgiliyim" ifadesi en yüksek ortalamaya $(3,555)$ sahiptir. En düşük ortalama ise $(2,965)$ "son birkaç haftadır heyecanlıyım" ifadesine aittir.

Katılımcıların olumsuz duygu durumlarını ölçmek amacıyla oluşturulan ifadelere verilen yanıtlar incelendiğinde "son birkaç haftadır kaygılıyım" ifadesi en yüksek ortalamaya $(3,330)$ sahiptir. En düşük ortalama ise $(1,198)$ "Son birkaç haftadır suçlu hissediyorum " ifadesine aittir.

Tablo 3: Olumsuz Duygu Durumları Ölçeğinin Ortalama ve Standart Sapma Değerleri

\begin{tabular}{|l|c|c|}
\hline \multicolumn{1}{|c|}{ Değişkenler } & Ort. & Std.Sapma \\
\hline Son birkaç haftadır "Üzgünüm" & 2,826 & 1,359 \\
\hline Son birkaç haftadır "Ürkmüş" hissediyorum & 2,615 & 1,378 \\
\hline Son birkaç haftadır "Utanmış" hissediyorum & 1,939 & 1,207 \\
\hline Son birkaç haftadır "Keyifsizim" & 2,954 & 1,342 \\
\hline Son birkaç haftadır "Sinirliyim" & 2,905 & 1,296 \\
\hline Son birkaç haftadır "Suçlu" hissediyorum & 1,198 & 1,287 \\
\hline Son birkaç haftadır "Korkmuş" hissediyorum & 2,165 & 1,261 \\
\hline Son birkaç haftadır "Sefil" hissediyorum & 2,236 & 1,418 \\
\hline Son birkaç haftadır "Gerginim" & 3,090 & 1,385 \\
\hline Son birkaç haftadır "Kaygılıyım" & 3,330 & 1,470 \\
\hline Son birkaç haftadır "Yalnızım" & 2,714 & 1,554 \\
\hline Son birkaç haftadır "Kızgınım" & 2,774 & 1,433 \\
\hline Son birkaç haftadır "İğrenmiş" hissediyorum & 2,088 & 1,401 \\
\hline
\end{tabular}

Katılımcıların online perakende terapi düzeylerini ölçmek amacıyla oluşturulan ifadelere verilen yanıtlar incelendiğinde "online alışveriş bana yeni stiller hakkında bilgi sağlıyor " ifadesi en yüksek ortalamaya $(3,624)$ sahiptir. En düşük ortalama ise $(2,126)$ "online alışveriş, başka şeyler kontrol dışı kaldığında, işleri kontrol etmenin bir yoludur." ifadesine aittir.

Tablo 4: Online Perakende Terapi Ölçeğinin Ortalama ve Standart Sapma Değerleri

\begin{tabular}{|c|c|c|}
\hline Değişkenler & Ort. & Std.Sapma \\
\hline Stresimi azaltmak için online alışveriş yaparım. & 2,500 & 1,431 \\
\hline Kendimi neşelendirmek için online alışveriş yaparım. & 2,652 & 1,454 \\
\hline Kendimi daha iyi hissetmek için online alışveriş yaparım. & 2,682 & 1,467 \\
\hline Kötü bir günü telafi etmek için online alışveriş yaparım. & 2,223 & 1,336 \\
\hline Rahatlamak için online alışveriş yaparım. & 2,450 & 1,471 \\
\hline İyi hissetmek için online alışveriş yaparım. & 2,495 & 1,505 \\
\hline Online alışveriş, olumlu bir dikkat dağıtıcıdır. & 2,950 & 1,411 \\
\hline Online alışveriş bana başarı hissi verir. & 2,042 & 1,238 \\
\hline Online alışverişteki görsel uyarımlardan hoşlanırım. & 2,933 & 1,399 \\
\hline Online alışveriş bana yeni stiller hakkında bilgi sağlıyor. & 3,624 & 1,250 \\
\hline Online alışverişin sağladığı hoş ortamda bulunmaktan zevk alırım & 2,890 & 1,430 \\
\hline Büyük bir şey bulmak, kendimle ilgili olumlu duygularımı güçlendirir. & 3,047 & 1,385 \\
\hline Online alışveriş yalnızlıktan kaçmaktır. & 2,148 & 1,263 \\
\hline Online alışveriş, stresli ortamlardan kurtulmamın bir yoludur & 2,418 & 1,373 \\
\hline Online alışveriş yapmak, beni rahatsız eden şeyleri aklımdan çıkarmanın bir yoludur. & 2,527 & 1,310 \\
\hline Yeni bir şey için online alışveriş yapmak boşluk duygusunu doldurur. & 2,532 & 1,324 \\
\hline Online alışveriş, başka şeyler kontrol dışı kaldığında, işleri kontrol etmenin bir yoludur. & 2,126 & 1,221 \\
\hline Moralimi düzeltmek için online alışveriş etkilidir. & 2,635 & 1,397 \\
\hline $\begin{array}{l}\text { Kendimi daha iyi hissetmek için yaptığım online alışverişten sonra, en azından günün } \\
\text { geri kalanı için en iyi hisler oluşur }\end{array}$ & 2,641 & 1,367 \\
\hline Moralimi düzeltmek için yaptığım online alışverişten sonra kendimi iyi hissederim & 2,858 & 1,393 \\
\hline Aldığım eşyaları moralimi düzeltmek için kullanırım. & 2,817 & 1,427 \\
\hline $\begin{array}{l}\text { Moralimi düzeltmek için yaptığım online alışveriş sırasında aldığım eşyaları } \\
\text { kullanırken, o online alışveriş deneyimini hatırlarım. }\end{array}$ & 2,656 & 1,407 \\
\hline
\end{tabular}

\section{Araştırmada kullanılan ölçeklerin güvenilirlik analizleri}

Ölçeklere ait güvenilirlik, Cronbach's Alpha katsayısı kullanılarak test edilmiştir. 0,70 ve üzerinde ölçülen Cronbach Alpha katsayısı ölçeğin güvenilir olduğunu ifade etmektedir (Durmuş, Yurtkoru, ve Çinko, 2013, s. 86). Aşağıda yer alan Tablo 5'te güvenilirlik sonuçları yer almaktadır. 
Tablo 5: Ölçeklerin Güvenilirlik Analizi Sonuçları

\begin{tabular}{|l|c|c|}
\hline \multicolumn{1}{|c|}{ Ölçekler } & n & $\begin{array}{c}\text { Cronbach Alpha } \\
\text { Katsayısı }\end{array}$ \\
\hline Olumlu Duygu Durumları & 15 & 0,914 \\
\hline Olumsuz Duygu Durumları & 13 & 0,914 \\
\hline Online Perakende Terapi & 22 & 0,963 \\
\hline
\end{tabular}

Araştırmada kullanılan ölçekler 0,914 ve 0,963 Cronbach Alpha katsayısı değerlerindedir. Bu sonuca göre kullanılan 3 ölçeğin de yüksek düzeyde güvenilir olduğu söylenebilir.

\section{Hipotezlerin testi}

Analize başlamadan önce yapılan normallik testlerinde ölçeklerin çarpıklık ve basıklık değerleri -/+ 1 değerleri aralığında olduğu için normal dağılımın sağlandığı söylenebilir (Hair, Black, Babin ve Anderson, 2013, s. 51).

Çalışmada hipotezleri test etmek amacıyla basit regresyon analizi yapılmıştır. Bu çalışmada ilk olarak $\mathrm{H}_{1}$ hipotezini test etmek amacıyla olumlu duygu durumlarını oluşturan tüm ifadelerin ve online perakende terapi ölçeğini oluşturan tüm ifadelerin ortalaması alınmış ve regresyon analizi yapılmıştır.

$H_{1}$ : Tüketicilerin olumlu duygu durumlarının online perakende terapi üzerinde istatistiksel olarak anlamlı bir etkisi vardır.

Yapılan regresyon analizi ile olumlu duygu durumlarının (bağımsız değişken), online perakende terapi üzerindeki etkisini tespit etmek amaçlanmıştır. Analiz sonuçları Tablo 6'da gösterilmiştir

Tablo 6: Olumlu Duygu Durumlarının Online Perakende Terapi Üzerindeki Etkisi

\begin{tabular}{|l|c|c|c|}
\hline \multicolumn{1}{|c|}{ Bağımsız Değişken } & $\begin{array}{c}\text { Standartlaştırılmış Beta } \\
\text { Katsayıları }\end{array}$ & T Değeri & P \\
\hline Sabit & - & 10,807 & 0,000 \\
\hline Olumlu Duygu Durumları &, 129 & 2,810 & 0,005 \\
\hline$R^{2}=0,017$ Ayarlanmış $\mathrm{R}^{2}=0,015$ & $\mathrm{~F}=7,897 \quad$ Anlamlılık Düzeyi $=0,005$ & \\
\hline
\end{tabular}

Analiz sonucuna göre online perakende terapi ölçeğinin \%1,5'ini olumlu duygu durumları faktörü açıklayabilmektedir. Tabloya göre $\mathrm{p}$ değeri $0,005^{\prime}$ dir. Bu durumda olumlu duygu durumlarının online perakende terapi üzerinde istatistiksel olarak anlamlı bir etkisi vardır sonucuna ulaşılabilir. Standardize edilmiş Beta katsayısı incelendiğinde bu etkinin pozitif yönlü olduğu söylenebilir. $\mathrm{H}_{1}$ hipotezi kabul edilmiştir.

Olumlu duygu durumunun online perakende terapi ölçeğinin alt boyutları olan terapatik alışveriş motivasyonları, pozitif duygu takviyesi, negatif duygu durum azalması ve terapatik alışveriş sonucu değişkenlerinin üzerindeki etkisini incelemek amacıyla regresyon analizi yapılmıştır.

$\mathrm{H}_{1 a}$ : Tüketicilerin olumlu duygu durumlarının terapatik alışveriş motivasyonları değişkeni üzerinde istatistiksel olarak anlamlı bir etkisi vardır

Tablo 7: Olumlu Duygu Durumlarının Terapatik Alışveriş Motivasyonları Üzerindeki Etkisi

\begin{tabular}{|l|c|c|c|}
\hline \multicolumn{1}{|c|}{ Bağımsız Değişken } & $\begin{array}{c}\text { Standartlaştırılmış Beta } \\
\text { Katsayıları }\end{array}$ & T Değeri & P \\
\hline Sabit & - & 7,513 & 0,000 \\
\hline Olumlu Duygu Durumları &, 119 & 2,582 & 0,010 \\
\hline $\mathrm{R}^{2}=0,014$ Ayarlanmış $\mathrm{R}^{2}=0,012$ & $\mathrm{~F}=6,666 \quad$ Anlamlılık Düzeyi $=0,010$ & \\
\hline
\end{tabular}

Analiz sonucuna göre terapatik alışveriş motivasyonlarının $\% 0,12$ 'sini olumlu duygu durumları faktörü açıklayabilmektedir. Tabloya göre $\mathrm{p}$ değeri 0,010 'dur. $\mathrm{Bu}$ durumda olumlu duygu durumlarının terapatik alışveriş motivasyonları üzerinde istatistiksel olarak anlamlı bir etkisi vardır sonucuna ulaşılabilir. Standardize edilmiş Beta katsayısı incelendiğinde bu etkinin pozitif yönlü olduğu söylenebilir. Hia hipotezi kabul edilmiştir.

Hıb: Tüketicilerin olumlu duygu durumlarının terapatik alışveriş değeri pozitif duygu takviyesi değişkeni üzerinde istatistiksel olarak anlamlı bir etkisi vardır. 
Tablo 8: Olumlu Duygu Durumlarının Terapatik Alışveriş Değeri Pozitif Duygu Takviyesi Üzerindeki Etkisi

\begin{tabular}{|l|c|c|c|}
\hline \multicolumn{1}{|c|}{ Bağımsız Değişken } & $\begin{array}{c}\text { Standartlaştırılmış Beta } \\
\text { Katsayıları }\end{array}$ & T Değeri & P \\
\hline Sabit & - & 11,751 & 0,000 \\
\hline Olumlu Duygu Durumları &, 182 & 3,992 & 0,000 \\
\hline$R^{2}=0,033$ Ayarlanmış $R^{2}=0,031 \quad$ F=15,939 Anlamlılık Düzeyi $=0,000$ & \multicolumn{2}{|c|}{ A } \\
\hline
\end{tabular}

Analiz sonucuna göre terapatik alışveriş değeri pozitif duygu takviyesi $\% 0,31^{\prime} \mathrm{i}$ olumlu duygu durumları faktörü açiklayabilmektedir. Tabloya göre p değeri 0,000 ‘dur. Bu durumda olumlu duygu durumlarının terapatik alışveriş değeri pozitif duygu takviyesi üzerinde istatistiksel olarak anlamlı bir etkisi vardır sonucuna ulaşılabilir. Standardize edilmiş Beta katsayısı incelendiğinde bu etkinin pozitif yönlü olduğu söylenebilir. H1b hipotezi kabul edilmiştir.

Hıc: Tüketicilerin olumlu duygu durumlarının terapatik alışveriş değeri negatif duygu durumu azalması değişkeni üzerinde istatistiksel olarak anlamlı bir etkisi vardır.

Tablo 9: Olumlu Duygu Durumlarının Terapatik Alışveriş Değeri Negatif Duygu Durum Azalması Üzerindeki Etkisi

\begin{tabular}{|l|c|c|c|}
\hline \multicolumn{1}{|c|}{ Bağımsız Değişken } & $\begin{array}{c}\text { Standartlaştırılmış Beta } \\
\text { Katsayıları }\end{array}$ & T Değeri & P \\
\hline Sabit & - & 10,283 & 0,000 \\
\hline Olumlu Duygu Durumları &, 049 & 1,048 & 0,295 \\
\hline $\mathrm{R}^{2}=0,002$ Ayarlanmış $\mathrm{R}^{2}=0,000$ & $\mathrm{~F}=1,099 \quad$ Anlamlılık Düzeyi $=0,000$ & \\
\hline
\end{tabular}

Tabloya göre $\mathrm{p}$ değeri 0,295 'dir. Bu durumda olumlu duygu durumlarının terapatik alışveriş değeri negatif duygu durum azalması üzerinde istatistiksel olarak anlamlı bir etkisi olmadığı sonucuna ulaşılabilir. Hıc hipotezi reddedilmiştir.

Hı: Tüketicilerin olumlu duygu durumlarının terapatik alışveriş sonucu değişkeni üzerinde istatistiksel olarak anlamlı bir etkisi vardır.

Tablo 10: Olumlu Duygu Durumlarının Terapatik Alışveriş Sonucu Üzerindeki Etkisi

\begin{tabular}{|l|c|c|c|}
\hline \multicolumn{1}{|c|}{ Bağımsız Değişken } & $\begin{array}{c}\text { Standartlaştırılmış Beta } \\
\text { Katsayıları }\end{array}$ & T Değeri & P \\
\hline Sabit & - & 9,502 & 0,000 \\
\hline Olumlu Duygu Durumları &, 102 & 2,215 & 0,027 \\
\hline $\mathrm{R}^{2}=0,10$ Ayarlanmış $\mathrm{R}^{2}=0,008$ & $\mathrm{~F}=4,907 \quad$ Anlamlılık Düzeyi $=0,027$ & \\
\hline
\end{tabular}

Analiz sonucuna göre terapatik alışveriş sonucunun \%0,08'ini olumlu duygu durumları faktörü açıklayabilmektedir. Tabloya göre $\mathrm{p}$ değeri 0,270 'dir. Bu durumda olumlu duygu durumlarının terapatik alışveriş sonucu üzerinde istatistiksel olarak anlamlı bir etkisi olduğu sonucuna ulaşılabilir. Standardize edilmiş Beta katsayısı incelendiğinde bu etkinin pozitif yönlü olduğu söylenebilir. $\mathrm{H}_{1 d}$ hipotezi kabul edilmiştir.

$\mathrm{H}_{2}$ hipotezini test etmek amacıyla olumsuz duygu durumlarını oluşturan tüm ifadelerin ve online perakende terapi ölçeğini oluşturan tüm ifadelerin ortalaması alınmış ve regresyon analizi yapılmıştır

$\mathrm{H}_{2}$ : Tüketicilerin olumsuz duygu durumlarının online perakende terapi üzerinde istatistiksel olarak anlamlı bir etkisi vardır.

Tablo 11: Olumsuz Duygu Durumlarının Online Perakende Terapi Üzerindeki Etkisi

\begin{tabular}{|l|c|c|c|}
\hline \multicolumn{1}{|c|}{ Bağımsız Değişken } & $\begin{array}{c}\text { Standartlaştırılmış Beta } \\
\text { Katsayıları }\end{array}$ & T Değeri & P \\
\hline Sabit & - & 16,850 & 0,000 \\
\hline Olumlu Duygu Durumları &, 115 & 2,499 & 0,013 \\
\hline $\mathrm{R}^{2}=0,013$ Ayarlanmış $\mathrm{R}^{2}=0,011$ & $\mathrm{~F}=6,243 \quad$ Anlamlılık Düzeyi=0,013 \\
\hline
\end{tabular}


Analiz sonucuna göre online perakende terapi ölçeğinin \%0,11'ini olumsuz duygu durumları faktörü açıklayabilmektedir. Tabloya göre $\mathrm{p}$ değeri 0,013 'dür. Bu durumda olumsuz duygu durumlarının online perakende terapi üzerinde istatistiksel olarak anlamlı bir etkisi vardır sonucuna ulaşılabilir. Standardize edilmiş Beta katsayısı incelendiğinde bu etkinin pozitif yönlü olduğu söylenebilir. Yani $\mathrm{H}_{2}$ hipotezi kabul edilmiştir.

Olumsuz duygu durumunun online perakende terapi ölçeğinin alt boyutları olan terapatik alışveriş motivasyonları, pozitif duygu takviyesi, negatif duygu durum azalması ve terapatik alışveriş sonucu değişkenlerinin üzerindeki etkisini incelemek amacıyla regresyon analizi yapılmıştır.

$\mathrm{H}_{2 a}$ : Tüketicilerin olumsuz duygu durumlarının terapatik alışveriş motivasyonları değişkeni üzerinde istatistiksel olarak anlamlı bir etkisi vardır.

Tablo 12: Olumsuz Duygu Durumlarının Terapatik Alışveriş Motivasyonları Üzerindeki Etkisi

\begin{tabular}{|l|c|c|c|}
\hline \multicolumn{1}{|c|}{ Bağımsız Değişken } & $\begin{array}{c}\text { Standartlaştırılmış Beta } \\
\text { Katsayıları }\end{array}$ & T Değeri & P \\
\hline Sabit & - & 13,452 & 0,000 \\
\hline Olumlu Duygu Durumları &, 119 & 0,732 & 0,465 \\
\hline $\mathrm{R}^{2}=0,001 \quad$ Ayarlanmıs $\mathrm{R}^{2}=-0,001$ & $\mathrm{~F}=0,536 \quad$ Anlamlılık Düzeyi $=0,465$ & \\
\hline
\end{tabular}

Tabloya göre $\mathrm{p}$ değeri $0,465^{`}$ dir. Bu durumda olumsuz duygu durumlarının terapatik alışveriş motivasyonları üzerinde istatistiksel olarak anlamlı bir etkisi olmadığı sonucuna ulaşılabilir. $\mathrm{H}_{2 a}$ hipotezi reddedilmiştir.

$\mathrm{H}_{2 b}$ : Tüketicilerin olumsuz duygu durumlarının terapatik alışveriş değeri pozitif duygu takviyesi değişkeni üzerinde istatistiksel olarak anlamlı bir etkisi vardır.

Tablo 13: Olumsuz Duygu Durumlarının Terapatik Alışveriş Değeri Pozitif Duygu Takviyesi Üzerindeki Etkisi

\begin{tabular}{|l|c|c|c|}
\hline \multicolumn{1}{|c|}{ Bağımsız Değişken } & $\begin{array}{c}\text { Standartlaştırılmış Beta } \\
\text { Katsayıları }\end{array}$ & T Değeri & P \\
\hline Sabit & - & 21,605 & 0,000 \\
\hline Olumlu Duygu Durumları &, 011 & 0,236 & 0,813 \\
\hline $\mathrm{R}^{2}=0,000$ Ayarlanmış $\mathrm{R}^{2}=-0,002$ & $\mathrm{~F}=0,056 \quad$ Anlamlılık Düzeyi $=0,813$ & \\
\hline
\end{tabular}

Tabloya göre $\mathrm{p}$ değeri 0,813 ‘dür. Bu durumda olumsuz duygu durumlarının terapatik alışveriş değeri pozitif duygu takviyesi üzerinde istatistiksel olarak anlamlı bir etkisi olmadığı sonucuna ulaşılabilir. $\mathrm{H}_{2 b}$ hipotezi reddedilmiştir.

$\mathrm{H}_{2 c}$ : Tüketicilerin olumsuz duygu durumlarının terapatik alışveriş değeri negatif duygu durumu azalması değişkeni üzerinde istatistiksel olarak anlamlı bir etkisi vardır.

Tablo 14: Olumsuz Duygu Durumlarının Terapatik Alışveriş Değeri Negatif Duygu Durum Azalması Üzerindeki Etkisi

\begin{tabular}{|l|c|c|c|}
\hline \multicolumn{1}{|c|}{ Bağımsız Değişken } & $\begin{array}{c}\text { Standartlaştırılmış Beta } \\
\text { Katsayıları }\end{array}$ & T Değeri & P \\
\hline Sabit & - & 11,192 & 0,000 \\
\hline Olumlu Duygu Durumları &, 259 & 5,771 & 0,000 \\
\hline $\mathrm{R}^{2}=0,067$ Ayarlanmış $\mathrm{R}^{2}=0,065$ & $\mathrm{~F}=33,300 \quad$ Anlamlılık Düzeyi $=0,000$ & \\
\hline
\end{tabular}

Analiz sonucuna göre negatif duygu durum azalması ölçeğinin \%0,65'ini olumsuz duygu durumları faktörü açıklayabilmektedir. Tabloya göre $p$ değeri 0,000 'dır.Bu durumda olumsuz duygu durumlarının negatif duygu durum azalması üzerinde istatistiksel olarak anlamlı bir etkisi vardır sonucuna ulaşılabilir. Standardize edilmiş Beta katsayısı incelendiğinde bu etkinin pozitif yönlü olduğu söylenebilir. Yani $\mathrm{H}_{2 c}$ hipotezi kabul edilmiştir.

$\mathrm{H}_{2 \mathrm{~d}}$ : Tüketicilerin olumsuz duygu durumlarının terapatik alışveriş sonucu değişkeni üzerinde istatistiksel olarak anlamlı bir etkisi vardır. 
Tablo 15: Olumsuz Duygu Durumlarının Terapatik Alışveriş Sonucu Üzerindeki Etkisi

\begin{tabular}{|l|c|c|c|}
\hline \multicolumn{1}{|c|}{ Bağımsız Değişken } & $\begin{array}{c}\text { Standartlaştırılmış Beta } \\
\text { Katsayıları }\end{array}$ & T Değeri & P \\
\hline Sabit & - & 13,787 & 0,000 \\
\hline Olumlu Duygu Durumları &, 139 & 3,031 & 0,003 \\
\hline $\mathrm{R}^{2}=0,19$ Ayarlanmış $\mathrm{R}^{2}=0,017$ & $\mathrm{~F}=9,188 \quad$ Anlamlılık Düzeyi $=0,003$ & \\
\hline
\end{tabular}

Analiz sonucuna göre terapatik alışveriş sonucunun $\% 0,17^{\prime}$ sini olumsuz duygu durumları faktörü açıklayabilmektedir. Tabloya göre $\mathrm{p}$ değeri 0,003 ‘dür. Bu durumda olumsuz duygu durumlarının terapatik alışveriş sonucu üzerinde istatistiksel olarak anlamlı bir etkisi vardır sonucuna ulaşılabilir. Standardize edilmiş Beta katsayısı incelendiğinde bu etkinin pozitif yönlü olduğu söylenebilir. $\mathrm{H}_{2 \mathrm{~d}}$ hipotezi kabul edilmiştir.

\section{Sonuç}

Alışveriş günlük hayatın bir parçası haline gelmiştir ve bireyler olumsuz duygulardan kurtulmak için alışverişe yönelebilmektedir. Özellikle kolay ulaşımı ve birçok alternatifi bir arada görebilmeleri sebebiyle online alışveriş birçok tüketicinin ilk durağı olmaktadır.

Bu çalışma, tüketicilerin olumsuz ve olumlu duygu durumlarının online perakende terapi üzerinde etkisi olup olmadığı sorusunu açıkça ele almıştır. Çalışmada 466 kullanılabilir veri elde edilmiştir. Katılımcıların çoğunluğunu kadınlar oluşturmaktadır. Çoğunluk evli, lisans mezunu, 19-30 yaş aralığında 3.501-5.000 TL arası gelire sahip ve özel sektör çalışanlarıdır. Literatüre dayanarak son birkaç haftadaki duygu durumları sorulduğunda ilgiliyim ifadesi en yüksek ortalama sahip yanıt olmuştur. Suçlu hissediyorum ifadesi ise en düşük ortalamaya sahip olan ifadedir. Ayrıca online alışveriş bana yeni stiller hakkında bilgi sağlıyor ifadesine katılım yüksektir. Bunu "büyük bir şey bulmak, kendimle ilgili olumlu duygularımı güçlendirir" ifadesi takip etmektedir. "Online alışveriş, başka şeyler kontrol dışı kaldığında, işleri kontrol etmenin bir yoludur" ifadesi ise düşük katılıma sahiptir.

Çalışmada olumlu duyguların online perakende terapi üzerinde etkisi olduğu sonucuna ulaşılmıştır. Yani tüketiciler kendilerini iyi hissettikleri zamanlarda da bu iyi his, online alışveriş yapmalarını sağlayabilmektedir. Bu sonuç Lee (2015)'nin araştırması ile desteklenmektedir. Ayrıca Gardner ve Rook (1998)'da yaptıkları deneysel çalışmada katılımcıları alışverişe teşvik eden duygulardan birinin "zevk" olduğu sonucuna ulaşmıştır. Online perakende terapi ölçeğinin boyutları incelendiğinde ise olumlu duygu durumu terapatik alışveriş motivasyonları, pozitif duygu takviyesi ve terapatik alışveriş sonucu üzerinde pozitif yönde etkiye sahipken negatif duygu durumu azalması üzerinde ise istatistiksel olarak anlamlı bir etkisi yoktur. Bunun sebebi katılımciların zaten olumlu duygulara sahip olması olabilir.

Çalışmada ayrıca olumuz duygu durumlarının da online perakende terapi üzerinde etkisi olduğu sonucuna ulaşılmıştır. Yani tüketiciler olumsuz duygulara sahip olduğu dönemlerde kendilerini iyi hissetmek amacıyla alışveriş yapabilmektedir. Bu sonuç yine literatürdeki çalışmalarla uyuşmaktadır (Lee, 2015)(Gardner ve Rook, 1998)(Trampe ve Stapel, 2011). Yine perakende terapi ölçeğini alt boyutları incelendiğinde olumsuz duygu durumlarının terapatik alışveriş motivasyonları ve pozitif duygu takviyesi üzerinde etkisinin olmadığı görülmüştür. Buna karşın negatif duygu durum azalması ve terapatik alışveriş sonucu üzerinde etkisi olduğu sonucuna ulaşılmıştır.

Literatürde bu konuda yapılmış araştırma çok fazla olmadığı için sonuçları karşılaştırmak ve yorumlamak biraz daha zor olmaktadır. Online alışveriş özellikle günümüzde bu kadar artmışken firmalar ve akademisyenler tarafından perakende terapi kavramı özellikle ele alınması gereken bir konudur. Çalışma Türkçe literatüre, online perakende terapi alanında yapılan ilk çalışma olması sebebiyle katkıda bulunmaktadır. Kavram aynı zamanda olumlu ve olumsuz duyguları birlikte ele alması yönünden ve bu duyguların online perakende terapi kavramına etkisini incelemesi yönünden önemlidir. Akademik açıdan bakıldığında tüketici duygularının ve ruh hallerinin satın alma üzerinde ki etkisinin önemi bu çalışma ile vurgulanmıştır. Tüketicilerin kara kutusu olan zihinlerinde, duygularında önemli etkisinin olduğu belirtilmiştir. Tüketici davranışlarını anlamada duygu durumlarının önemine vurgu yapılması gerektiği anlaşılmaktadır. Pazarlamacılar bu kanıtları Türk tüketiciler için daha uygun bir online perakende pazarlama stratejisi geliştirmek için kullanabilirler. 
Tüketicilerin ruh hallerini iyileştirmek ve pozitif duygularını arttırmak veya korumak için alışverişe yönelmeleri perakendeciler içinde önemli bir konudur. Pazarlamacılar için perakende terapi, ürünlerini tanıtmada ve tüketicilerle iletişim kurmada faydalıdır. Firmalar tüketicilerini takip ederek alışveriş sırasında ve sonrasında pozitif deneyimler yaşatarak tüketici zihninde olumlu bir imaj elde edebilir ve bu durum sayesinde marka sadakati yaratabilir. Terapi alışverişi yapanların terapatik alışveriş deneyimlerini genişletmelerine ve terapi alışveriş gezileri sırasında satın aldıkları ürünlerin terapatik değerlerini hatırlamalarına yardımcı olabilir. Bu deneyimler, bu müşterileri, olumsuz bir ruh halini hafifletmek istediklerinde perakendeciye (yani mağaza sadakatine) dönmeye teşvik edebilir. Alışveriş, günümüz tüketicisi için sadece ürünlere sahip olmanın ötesinde anlamlara sahiptir. Tüketicileri rahatlatmak için olumlu duygular yaratarak, günlük yaşamın stresinden kaçmayı, sorunlarından uzaklaşmayı ve de daha iyi hissetmeyi sağlar. Bu sebeple özellikle, alışveriş, bu çalışmanın sonuçları COVID-19 pandemi dönemine de uygulanabilir.

\section{Araştırmanın kısıtları}

Araştırmanın en önemli kıstı tesadüfi olmayan örnekleme yöntemlerinden kolayda örnekleme yolu ile verilerin toplanmış olması sebebiyle sonuçların genellemeyeceğidir.

Gelecek çalışmalarda araştırmacılar bu konuyu tüketicilerin demografik özellikleri açısından inceleyebilirler. Ayrıca yabancı literatürde perakende terapi kavramı sık sık anlık satın alma davranışı, materyalizm gibi konularla incelenmiştir. Bu değişkenler eklenerek bir araştırma yapılabilir.

\section{Hakem Değerlendirmesi / Peer-review:}

Dış bağımsız

Externally peer-reviewed

\section{Çıkar Çatışması / Conflict of interests:}

Yazar(lar) çıkar çatışması bildirmemiştir.

The author(s) has (have) no conflict of interest to declare.

\section{Finansal Destek / Grant Support:}

Yazar(lar) bu çalışma için finansal destek almadığını beyan etmiştir.

The author(s) declared that this study has received no financial support.

Etik Kurul Onayı / Ethics Committee Approval: Bu çalışma için etik kurul onayı, Erciyes Üniversitesi, Sosyal ve Beşerî Bilimler Etik Kurulundan 30/03/2021 tarihli 139 sayılı karar ile alınmıştır.

Ethics committee approval was received for this study from Erciyes University, Social and Humanities Ethics Committee on 30/03/2021 and 139 document number.

\section{Yazar Katkıları / Author Contributions:}

Fikir/Kavram/Tasarım -Idea/Concept/ Design: K.UVeri Toplama ve/veya İşleme - Data Collection and/orProcessing: K.U, S.T.P., Analiz ve/veya Yorum - Analysis and/orInterpretation:S.T.P., Kaynak Taraması - LiteratureReview:S.T.P., Makalenin Yazımı - WritingtheArticle: K.U, S.T.P., Eleştirel İnceleme - Critical Review: K.U, Onay -Approval: K.U, S.T.P. 


\section{Kaynakça / References}

Andrade, E.B. (2005). Behavioural consequences of affect: combining evaluative and regulatory mechanisms, Journal of Consumer Research, 32 (12), 355-362.

Atalay, A., ve Meloy, M. G. (2011). Retail Therapy: A Strategic Effort to Improve Mood. Psychology \& Marketing, 28 (6), 638-660.

Babin, B. J., Griffin, M., Borges, A., ve Boles, J. S. (2013). Negative emotions, value and relationships: Differences between women and men. Journal of Retailing and Consumer Service, 20 (5), 471-478.

Bui, M., ve Kemp, E. (2013). E-tail emotion regulation: examining online hedonic product purchases. International Journal of Retail \& Distribution Management, 41 (2), 155-170.

Durmuş, B., Yurtkoru, E., ve Çinko, M. (2013). "Sosyal Bilimlerde SPSS'le Veri Analizi". İstanbul: Beta.

Edwards, E. (1993). Development of a new scale for measuring compulsive buying behaviour. Financial Counseling and Planning , 67-84.

Gardner, M., ve Rook, D. (1998). Effects of impulse purchases on consumers' affective states. Advances in Consumer Research. 15, 127-130.

Hair, J. F., Black, W. C., Babin, B. J., ve Anderson, R. E. (2013). Multivariate Data Analysis. Pearson Education Limited.

Kacen, J. (1998). Retail therapy: Consumers' shopping cures for negative moods. Advances in consumer research, 25 (1), 75-87.

Kang, M., ve Johnson, K. K. (2011). Retail Therapy: Scale Development. Clothing \& Textiles, 29 (1), 3-19.

Ko, E., Chun, E., Song, S., ve Mattila, P. (2015). Exploring SNS as a consumer tool for retail therapy: explicating semantic networks of "shopping makes me happy (unhappy)" as a new product development method. Journal of Global Scholars of Marketing Science, 25 (1), 37-48.

Kumar, K. S., ve Sultana, M. (2017). Enhancing Customer Experience Through Retail Therapy. International Journal of Commerce and Managerial Science Research, 1 (1), 16-19.

Laros, F., ve Steenkamp, J. (2005). Emotion in consumer behaviour: a hierarchical approach. Journal of Business Research , 1437-1445.

Lee, J., ve Lee, Y. (2019). Does online shopping make consumers feel better? Exploring online retail therapy effects on consumers' attitudes towards online shopping malls. Asia Pacific Journal of Marketing and Logistics .

Lee, J., ve Lee, Y. (2019). Does online shopping make consumers feel better? Exploring online retail therapy effects on consumers' attitudes towards online shopping malls. Asia Pacific Journal of Marketing and Logistics .31 (2) , 464-479.

Lee, L. (2015). The Emotional Shopper: Assessing the Effectiveness of Retail Therapy. NowPress.Singapore.

Nayebzadeh, S. ve Jalaly, M.(2014). Investigating Iranian female Muslim consumer impulse buying behaviour used as a form of retail therapy.Journal of Islamic Marketing, 5 (2), 302-320.

Noh, M., ve Rakib ul Hasan, H. M. (2017). Moderating effect of personality traits on relationships between retail therapy, compulsive buying, and hoarding for fashion products. Journal of Global Fashion Marketing, 8 (3), 180-192.

Ortony, A. (1990). What's basic about basic emotions? Psychological review, 97 (3), 315.

Pereira, B., ve Rick, S. (2011). Why Retail Therapy Works: It Is Choice, Not Acquisition, That Primarily Alleviates Sadness. Association For Consumer Research , 738.

Rick, S., Pereira, B., ve Burson, K. (2014). The benefits of retail therapy: Making purchase decisions reduces residual sadness. Journal of Consumer Psychology, 24 (3), 373-380. 
Son, J., ve Chang, H. J. (2016). Retail Therapy: What Makes You Feel Relieved and Happy. International Textile and Apparel Association (ITAA) Annual Conference Proceedings.73. Iowa State University Digital Press.

Trampe, D., ve Stapel, D. A. (2011). Retail Therapy Or Rose-Tinted Glasses? the Effect of Mood on Impulse Buying. Association For Consumer Research, 38.

Tunjungsari, ,. H. (2011). Retail Therapy : Do Foreign Brands Give More Satisfaction Than Local Brands?http://repository.untar.ac.id/id/eprint/273

TÜBİSAD Ekonominin Dönüştürücü Gücü: E-Ticaret Etki Analizi 2020 Raporu, https://www.tubisad.org.tr/tr/images/pdf/tubisad-e-commerce_impact_assessmentlaunch presentation.pdf

Uyar,K., (2019). Perakende Terapi.Business E\&Manegeent Studies: An International Journal,7(1),496-513.

Watson,D., ve Clark,A.C., (1988).Development and Validation of Brief Measures of Positive and Negative Affect: the PANAS Scales. Journal of personality and social psychology, 54 (6), 1063-1070. 